\title{
ROLE OF DIFFERENT PARAMETERS IN THE QUANTIFICATION OF GENERATED SLUDGE IN THE OXYLATOR UNIT OF WATER TREATMENT PLANTS, USING ARTIFICIAL NEURAL NETWORK MODEL (CASE STUDY OF JALALIEH WATER TREATMENT PLANT, TEHRAN, IRAN)
}

\author{
NAEAMIKHAH, N. $.^{*}-$ NASRABADI, T. ${ }^{2}-$ SIRDARI, Z. Z. ${ }^{1}$ \\ ${ }^{I}$ Department of Environmental Engineering, Islamic Azad University, West Tehran Branch, \\ Tehran, Iran \\ ${ }^{2}$ Faculty of Environment, University of Tehran, Tehran, Iran \\ *Corresponding author \\ e-mail:naeamikhahh@gmail.com \\ (Received $2^{\text {nd }}$ Feb 2017; accepted $6^{\text {th }}$ Apr 2017)
}

\begin{abstract}
In recent years, smart imaging and error detection to achieve optimum performance in water and sewage treatment plants using Artificial Neural Network (ANN) detection technique has had a very active research field and has been regarded as one of the modern methods of modeling. This study has focused on predicting the sludge produced by the oxylator unit of the water treatment plant using an artificial neural network with multilayer Perceptron method. The measured input data: water flow, $\mathrm{pH}$, turbidity, temperature, free residual chlorine, conductivity, consumed lime, coagulant (ferric chloride), and magnum and the sludge produced by the oxylator were examined as output data of the model in two consecutive years 2014 and 2015. At the end, the results of neural network analysis were used to show the effect of each of the parameters in the production of sludge. According to the results, turbidity and $\mathrm{pH}$ are the most effective parameters in predicting the sludge produced by the oxylator unit of the water treatment plant. This study indicated that artificial neural network could achieve a 0.99 validity with a regression of 0.9881 and mean square error of 0.006 among the observed and predicted output variables of the model. In addition, artificial neural networks provide an effective tool to analyze the data to understand and simulate the nonlinear behavior of treatment plants.
\end{abstract}

Keywords: MLP, clarifier, disposal sludge, sludge quantity, solid wastage

\section{Introduction}

A water treatment plant not only produces drinking water, but is also a generator (inverter and generator) of solid waste. Solid wastages of the treatment plant are generally produced in coagulation and flocculation ponds and backwash filter unit. Sludge management is one of the important issues in water and wastewater treatment plants, including two major objectives of minimizing the sludge production in the treatment plant and treating it, and its user programs. The sludge quantity and properties are two main parameters influencing the management of the methods and costs of sludge treatment and disposal (AWWA, 1981). Modeling many ecological processes that are the effects of the interaction of factors that are firstly high in number and secondly create a complex system through interacting with each other is a difficult but important issue. Simulation of processes of water and waste water treatment plants are not excluded from this rule and usually face problems. Most available models are almost based on assumptions 
and probability. Lee and Park (1999) simulated the three important stages of water treatment, that are units including coagulation, flocculation, sedimentation and coagulant injection tanks equipped with pump at a pilot scale, Satheesh et al. (2013) equipped it with a feed forward control and measured three qualitative parameters of water including turbidity, electrical conductivity and raw water $\mathrm{pH}$ as the input data and the alum required for treatment as the output data, and then compared the results of these two models by modeling the numbers in artificial neural network and fuzzy logic network separately in order to optimize the dosage of coagulant. Results for the values of R and MSE for validation data on the structure of NN, were 0.8861 and 0.3215 respectively in the structure of ANFIS, and 0.8310 and 0.1161. Sengul and Gormez (2013) using neural network TurboProp2 algorithms and data of Büyükçekmece treatment plant in Turkey, modeled the optimal dose of the coagulant. They used the NeuroShell, that normalizes the data and does not need the pre-processing of data. At first they modeled the water qualitative parameters in the initial model, and in the second model, they modeled the optimal dose of coagulant. R and MSE values were 0.95 and 0.02 , respectively to predict $\mathrm{pH}, 0.7$ and 0.038 to predict the turbidity, 0.93 and 13.05 to predict electrical conductivity, 0.47 and 1.83 for color parameter, 0.54 and 0.000006 to predict the UV parameter, and 0.19 and 156.67 to predict Aluminum. Noorani et al. (2013) modeled and examined the qualitative parameters of electrical conductivity and TDS of Zarrin Rood water treatment plant, using perspetron neural network. They selected parameters of temperature, turbidity, total hardness, $\mathrm{pH}$ and calcium as input to the network, and used FFNN algorithms for modeling. To announce optimum model results, they used the comparison with empirical methods to assess the electrical conductivity and TDS, and found out that empirical equations used to estimate the electrical conductivity is not able to estimate the different variations in temperature, while neural network resists well against these changes and provides optimal results compared to experimental equations. D and RMSE results arising out of them for TDS output, with a structure of 1-5-5, are respectively, 0.81 and 0.028, and for outgoing EC, with a structure of 1-5-5, 0.73 and 0.037, respectively, and for TDS and EC output with a structure of 2-7-5, 0.74 and 0.059 , respectively and for TDS output, with a structure of $1-3-1$, is 0.98 and 0,007, respectively. Rak (2012) using Perspetron artificial neural network predicted the turbidity of Sosnówka water treatment plant in Poland with input data to models that include turbidity of raw water, tank input water, water level, daily rainfall and tank input water temperature and achieved the desired riteria of $\mathrm{R}=0.84$ and $\mathrm{RMSE}=0.49$.

$\mathrm{CP}$ (clean production) Methods, are integrated approaches to handling wastages and pollution in industries. (Visvanathan and Kumar, 1999). In addition, the importance of CP, has motivated leaders of different countries at different levels of industrial development to adopt national strategies and plan to accelerate the implementation of CP rules (Ghzinoory and Huisingh, 2006). CP principle represents the continuous proactive environmental approach to reduce pollution at the source of production. In addition, the ability of clean production methods is in developing clean systems and creating social and economic benefits (Zarkovic et al., 2011; Giannetti et al., 2008). Management of solid waste from a public health perspective as well as the social, economic and industrial function is very important, because with the constant increase in the quantity of production of 
dangerous or non-dangerous materials, they should be disposed safely and economically and preferably, with a recycle approach. Large amounts of waste water treatment materials result from drinking water treatment plants every year (Huang et al., 2005). Cleaner production has allowed industrial production to find a place in this vision by recasting negative impacts of polluting industrial processes and products into positive images of news technologies that are materials-conserving, energy- efficient, nonpolluting and low-waste, and that produce ecologically friendly products, like which are responsibly managed throughout their lifecycle (Geiser, 2001).

\section{Materials and methods}

The supply source of Jalalieh treatment plant is Karaj River in Beilaghan Basin. Raw water after removing sand and large brooms and preliminary chlorination in the basin is transferred to the treatment plant by two lines of steel pipes with a diameter of $1000 \mathrm{~mm}$ and a length of $40 \mathrm{~km}$ in gravity manner. Physical and microbiological treatment is performed along with some chemical filtration (refinement and reduction of some gases and heavy metals). Oxylator is a clarification unit under acceleration, which works based on mud workflow. In this clarifier, sludge is kept by the mixer in suspension and in circulation.

Artificial neural networks are information processing models that are inspired from the human brain neural networks. These networks consist of a large number of interconnected processing elements that work with each other in harmony. The idea of artificial neural networks began with the study of human brain cells. The idea of artificial neural networks began with the study of human brain cells. Human brain is made up of millions of unique neurons and these nerve fibers change in different shapes and sizes. Artificial neural networks consist of different parts. Components of an Artificial Neural Network include:

Input signals $\mathrm{X} 1$ to $\mathrm{Xn}$, are the equivalents of neural input signals and make up the total neuron input. The input, shown with vector $X$, can be the output of other layers.

Weight vector Wi1 to Win weights are the equivalents of neuron input synaptic connections values. The effect of input $\mathrm{Xi}$ on output $\mathrm{y}$ is measured by weight feature. Wi is adjustable and is moderated based on transformation functions and type of learning algorithm.

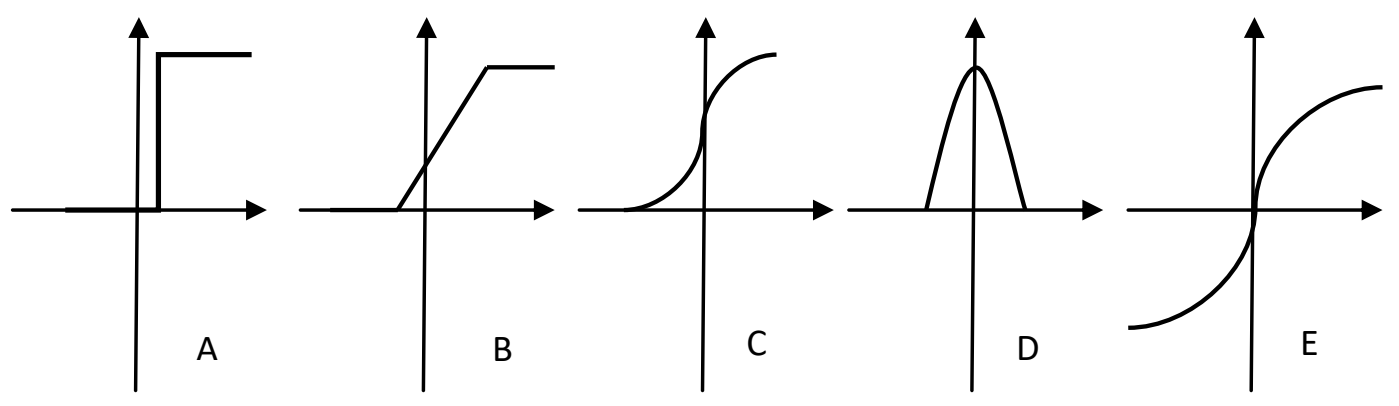

Figure 1. A) Threshold Function, B) Multi Piece Linear,

C) Sigmoid, D) Gaussian, E) Hyperbolic Tangent 
Aggregation Function defined by the following equation, performs the neuron processing. In one-neuron networks, the aggregation function to some extent determines the output and in multi-neuron networks, the aggregation function determines the level of activity of the neuron $\mathrm{j}$ in the inner layers.

$$
\text { Net } \mathbf{j}=\sum_{j=1}^{n} W_{i j} X i+b i
$$

bi: refers to bias, that is actually like a weight, except that its input is a constant 1 (Sun et al., 2016).

Activity Function also called compression function or transformation function; a function that determines the artificial neuron output values. Activation function maps a wide range of input values to a specific amount of output. There are various types of compression functions (Fig. 1).

Compression, hyperbolic tangent and sigmoid, functions are used the most. These functions are calculated through the following relationship (Funes et al., 2015):

$$
\begin{aligned}
& \text { Sigmoid function: } \mathrm{P}(\mathrm{t})=\frac{1}{1+e^{-1}} \\
& \text { Hyperbolictangentfunction: } Y=\frac{e^{x}-e^{-x}}{e^{x}+e^{-x}}
\end{aligned}
$$

Output refers to the response to the problem. The neuron output is determined by the following function:

$$
Y i=\text { ActivationFunction }\left(\sum_{j=1}^{n} X j W i j\right)
$$

Artificial neural network training process depends on several components and hence, a concept should be defined as network performance measurement. Then, the rules according to which the network performance should be set must also be defined. (Fig. 2) displays a schematic of the education network.

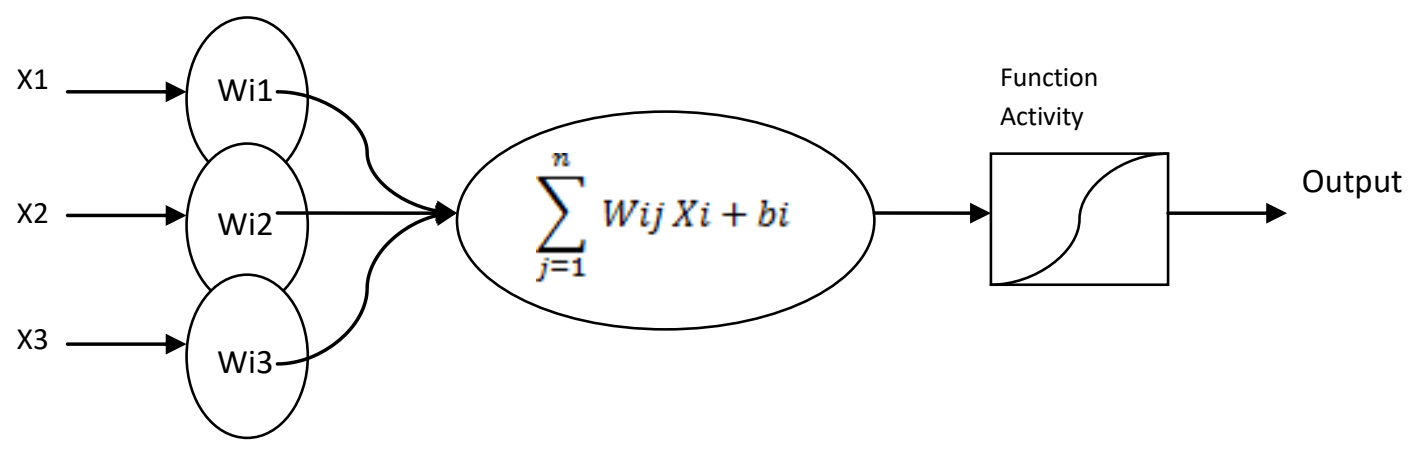

Figure 2. The structure of an artificial neurons 
Neural networks can be classified based on the concept of measuring network performance. When the network performance function is based on error measurements, the training is deemed as supervised. Normally, error is defined as the difference between network output and the favorable predefined response (Muthupriya et al., 2011). Common indices used to measure the performance of neural networks are given below (Djeddou and Achour, 2015). In all equations, T represents the actual output, $\overline{\mathrm{T}}$ represents the average actual output of the network, $\mathrm{O}$ represents the network output, $\overline{\mathrm{O}}$ represents the average network output and $\mathrm{N}$ is the total number of samples used.

Mean Square Error

Root Mean Square Error

Mean Absolute Percentage Error

Absolute Relative Error

The sum of squared errors

Regression coefficient

Coefficient of determination

$$
\operatorname{MSE}=\frac{1}{\mathrm{~N}} \sum_{\mathrm{i}=1}^{\mathrm{N}}(\mathrm{Ti}-\mathrm{Oi})^{2}
$$

Clasifications done on different structures of artificial neural networks are based on feedback and advance criteria. If at least one ring can be found in the network, in which one neuron returns to itself or to the past layer, the network is characterized as feedback. Feedback networks have more potential than advance networks and can better show the system time-related behavior characteristics. If in a neural network, the output of each neuron is connected only to the neurons of the next layer, it is deemed as advance. Advance neural network is also known as fully connected neural network, if each cell in each layer is connected to all the neurons in the input layer. But if some synaptic connections are removed, the resulting network is called partly connected (Fig. 3).

Multilayer Perceptron is one of the most commonly used types of neural networks (Vyas al., 2011).

In general, regarding the classification of staticpatterns, a Multilayer Perceptron with two medial layer, is used the most. In other words, separation functions can be used in these networks in any form. 


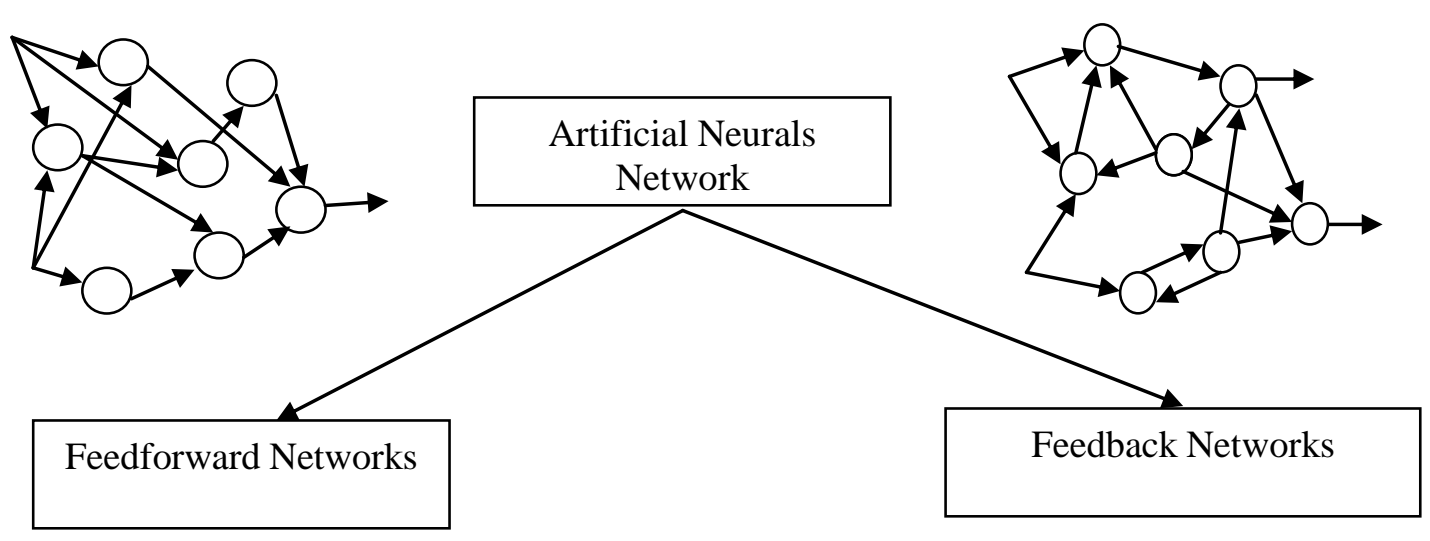

Figure 3. Netwok of feedforward or feedback

\section{Results and discussion}

The recorded data of water flow rate, input turbidity, temperature, electrical conductivity, $\mathrm{pH}$, lime consumption, free residual chlorine, the coagulant consumption and the contribution of the consumed coagulant was received during 22 consecutive months from operation control unit of the company. In addition, the daily production of sludge was extracted using the software SCADA by the operation unit. The Kolmogorov - Smirnov test that determines the normal distribution for the continuous quantitative variables was used with spss software version 19. The results indicate normality of sludge variables, free residual chlorine and the remaining $\mathrm{pH}$, while other variables are not normally distributed. For the normal results of the data, Pearson test was used for the correlation of the normal data, and Spearman correlation coefficient was used for non-normal data. In order to analyze the input data, the correlation between different parameters with each other as well as various parameters with the sludge produced by the oxylator unit was conducted using SPSS version 19. Pierson and Spearman's correlation coefficient was used because of the relativity of the variables used in this study (Table 1) (Cronbach, 1951).

Table 1. Correlation coefficient matrix of variables

\begin{tabular}{|c|c|c|c|c|c|c|c|c|c|c|}
\hline & Flow & Turbidity & Temprature & $\mathrm{Ec}$ & $\mathrm{pH}$ & $\mathrm{CaCo} 3$ & $\mathrm{Cl}_{2}$ & $\mathrm{FeCl}_{3}$ & Magnom & sludge \\
\hline \multicolumn{11}{|l|}{ Flow } \\
\hline Turbidity & -0.214 & 1 & & & & & & & & \\
\hline Temprature & 0.463 & -0.132 & 1 & & & & & & & \\
\hline $\mathrm{Ec}$ & -0.17 & -0.046 & -0.062 & 1 & & & & & & \\
\hline $\mathrm{pH}$ & 0.093 & 0.135 & 0.099 & -0.113 & 1 & & & & & \\
\hline $\mathrm{CaCo}_{3}$ & 0.213 & -0.022 & -0.189 & 0.331 & 0.007 & 1 & & & & \\
\hline $\mathrm{Cl} 2$ & -0.468 & -0.234 & -0.274 & 0.185 & -0.066 & 0.011 & 1 & & & \\
\hline $\mathrm{FeCl}_{3}$ & 0.325 & -0.059 & -0.24 & 0.25 & -0.037 & 0.893 & -0.032 & 1 & & \\
\hline Magnom & 0.488 & -0.258 & 0.115 & -0.131 & -0.278 & 0.008 & -0.278 & 0.139 & 1 & \\
\hline sludge & -0.01 & -0.003 & -0.253 & 0.09 & -0.111 & 0.163 & 0.001 & 0.187 & 0.063 & 1 \\
\hline
\end{tabular}


Different networks in terms of the number of hidden layer neurons and activation functions were created. Results of the table show that the correlation coefficient of lime consumption variable with ferric chloride is very high. Hence, by entering the variable values of the lime used as input data, the neural network model does not receive new data. Therefore, this parameter is ignored in the present simulation. Results of descriptive figure of the data used in the model are shown in Table 2.

Table 2. Matrix of statistical descriptions of model variables

\begin{tabular}{lcccc}
\hline & Min & Max & Mean & Std.Dev. \\
\hline Flow & 107800 & 24000 & 211547.46 & 16745.13 \\
Turbidity & 1.1 & 8.4 & 2.88 & 1.12 \\
Temprature & 6.3 & 33.6 & 13.34 & 3.81 \\
$\mathrm{Ec}$ & 231 & 1020 & 505.19 & 73.58 \\
$\mathrm{pH}$ & 7.45 & 8.5 & 8.09 & 0.15 \\
$\mathrm{CaCo}_{3}$ & 277 & 928 & 685.24 & 104.45 \\
$\mathrm{Cl}_{2}$ & 0.34 & 1.09 & 0.69 & 0.14 \\
$\mathrm{FeCl}_{3}$ & 774 & 2318 & 1740.09 & 222.59 \\
$\mathrm{Magnom}$ & 0 & 3 & 2.17 & 1.16 \\
sludge & 74 & 216 & 139.21 & 35.53 \\
\hline
\end{tabular}

In this study, the most commonly used method, which is the Levenberg-Marquardt training method, was used. In order to display the Network training, structure of (Fig. 4) was used.

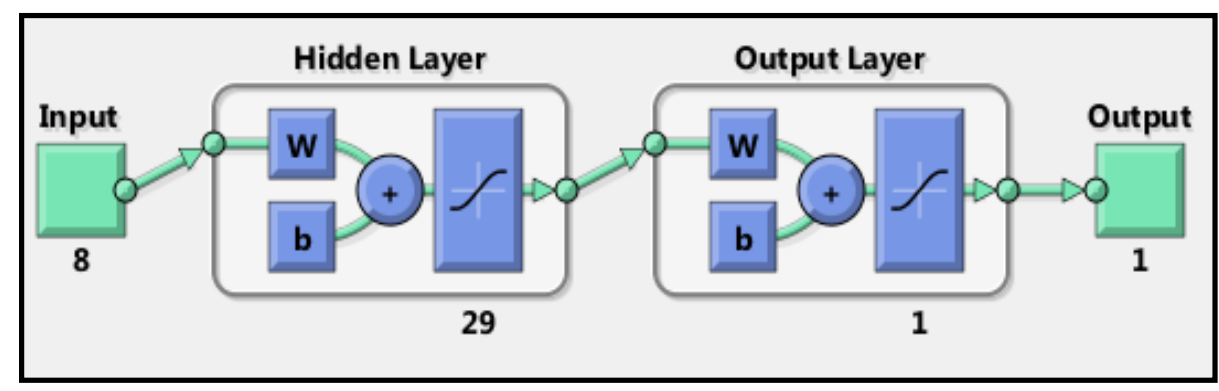

Figure 4. Structure of network training

Fig. 5 shows the results of network training to analyze regression coefficients in different structures are 1 to 30 neurons. Activation functions tansig- tansig are given in the order from left to right in the middle layer and output layer. The results including the correlation coefficient (R), the mean squared error (MSE) and root mean square error (RMSE) for each of the three categories (training,validation and testing) for each of the neurons in the middle layer are separated.

Fig. 6 shows network learning results to analyze error coefficients in different structures are 1 to 30 neurons. 


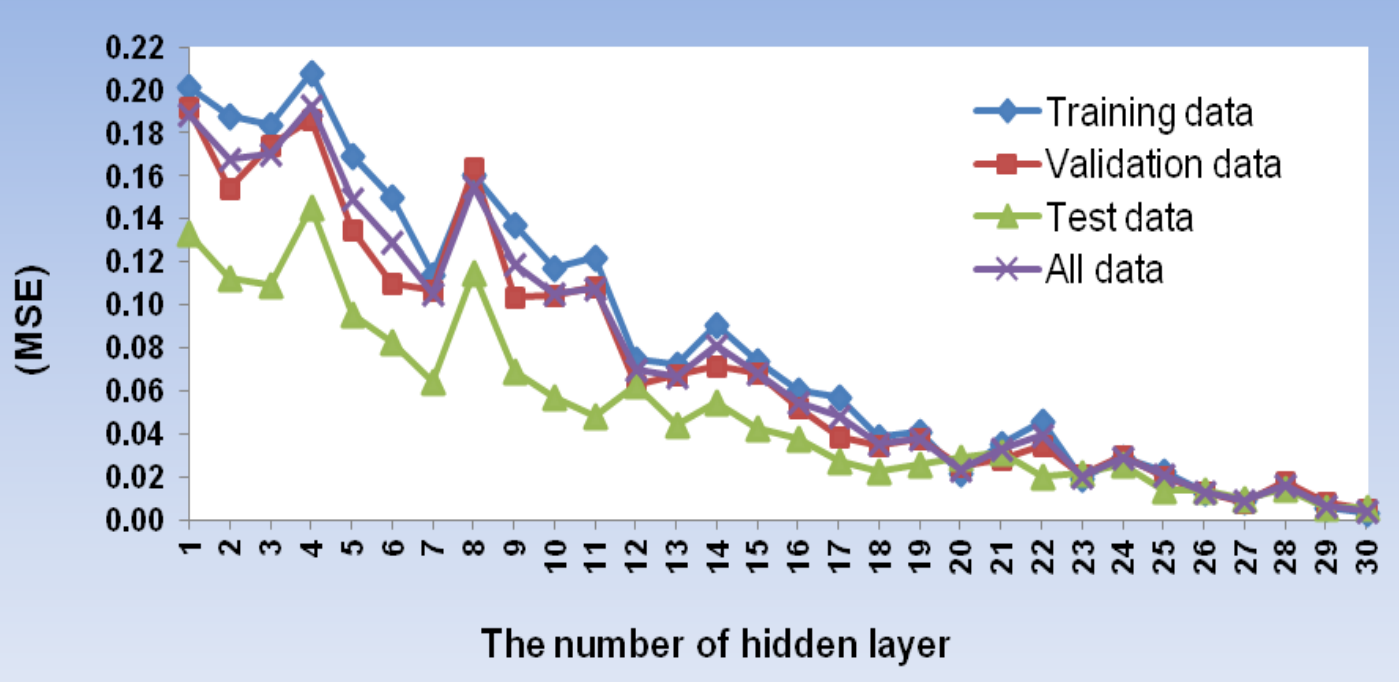

Figure 5. Analytical diagram of regression coefficients in training validation and testing data, for activities functions tansig-tansig

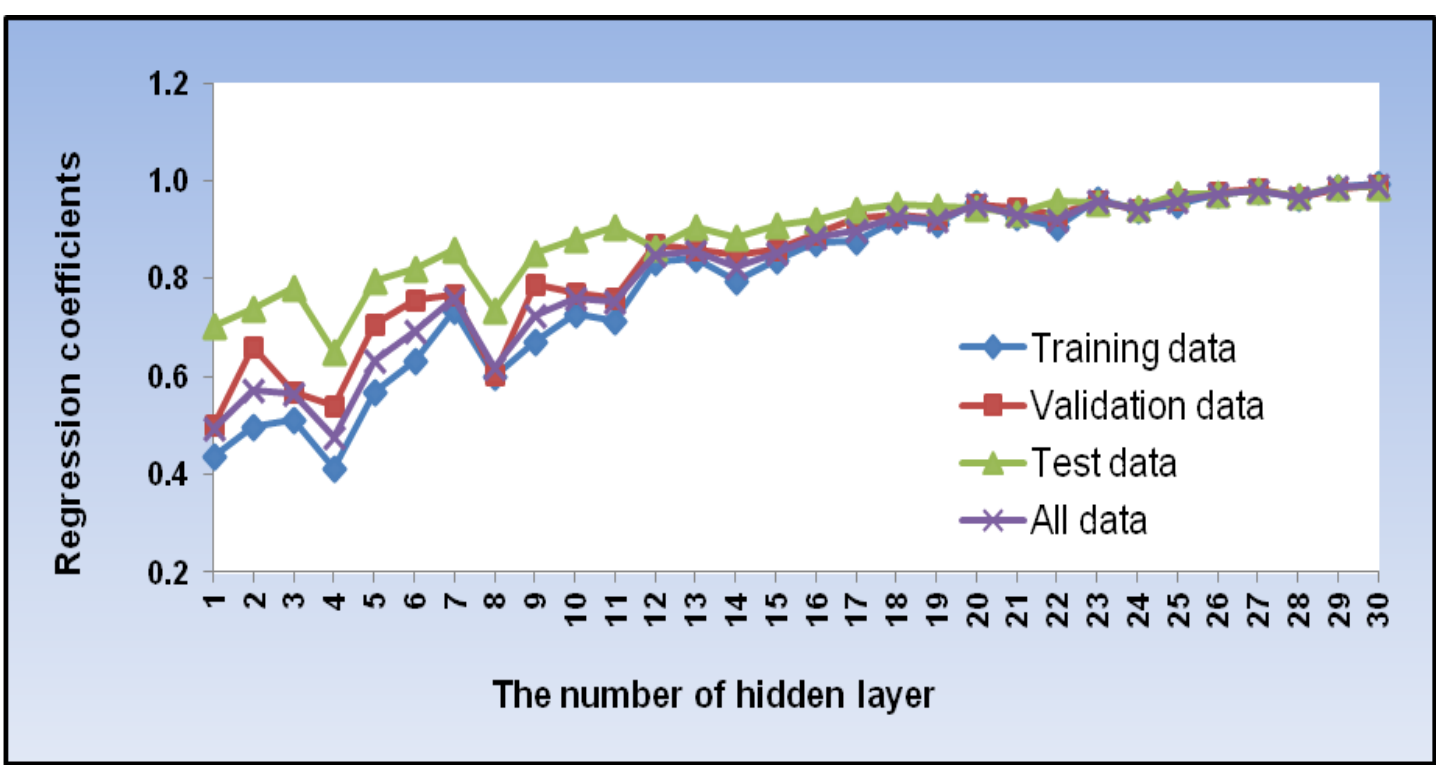

Figure 6. Analytical diagram of error coefficients in training validation and testing data, for activities functions tansig-tansig

Finally, the optimal number of neurons to predict network with the lowest error 29 neurons with activation functions tansig-tansig, is the desired choice for the network. Diagrams and values of regression and network error are according to (Fig. 7), (Fig. 8), (Fig. 9) and (Fig. 10) for all data, education data, validation data and test data related to the optimum network. For each of the main data and pre-processed data during network: 


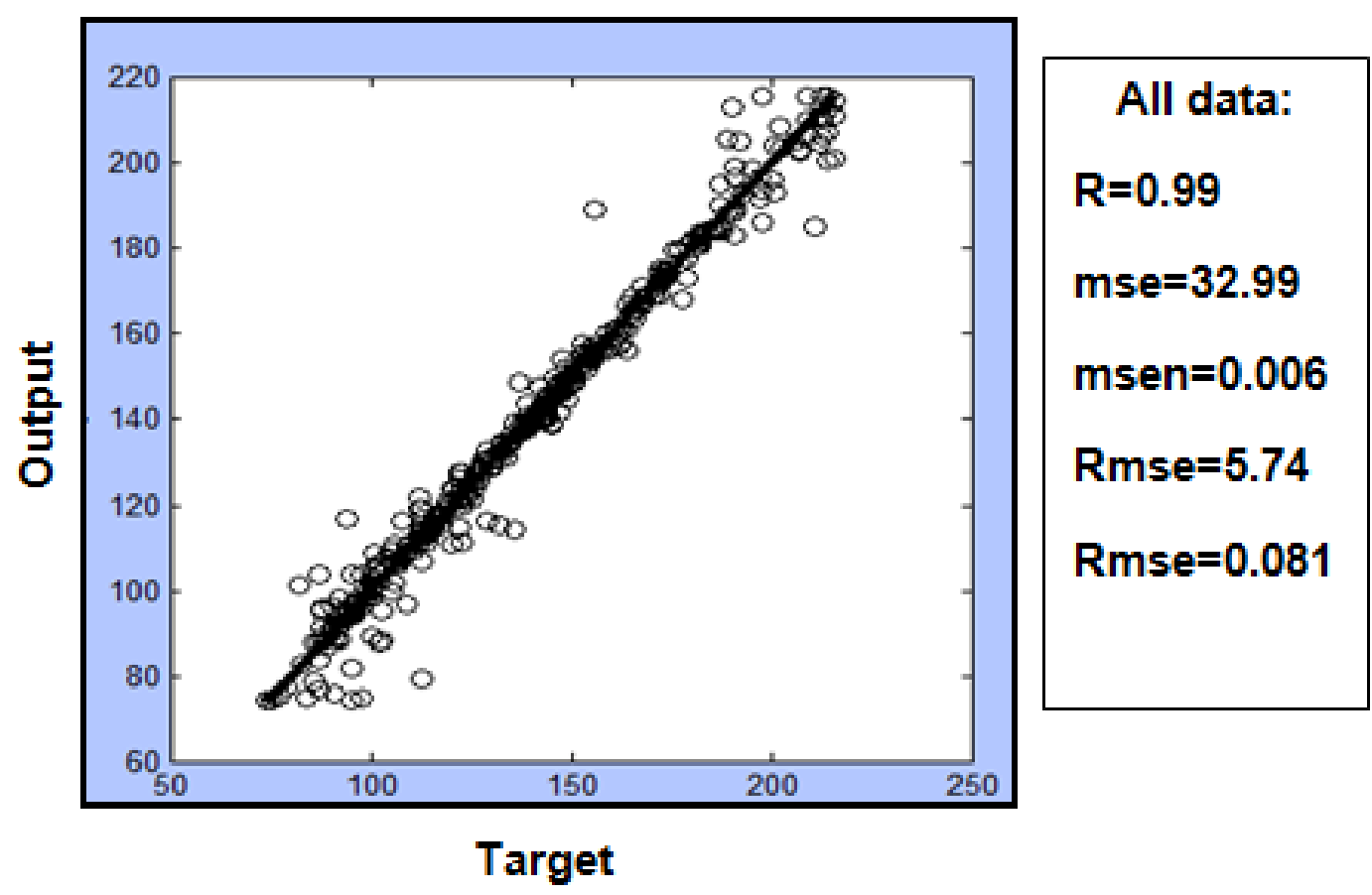

Figure 7. Values of $R-M S E-R M S E$ for all data set

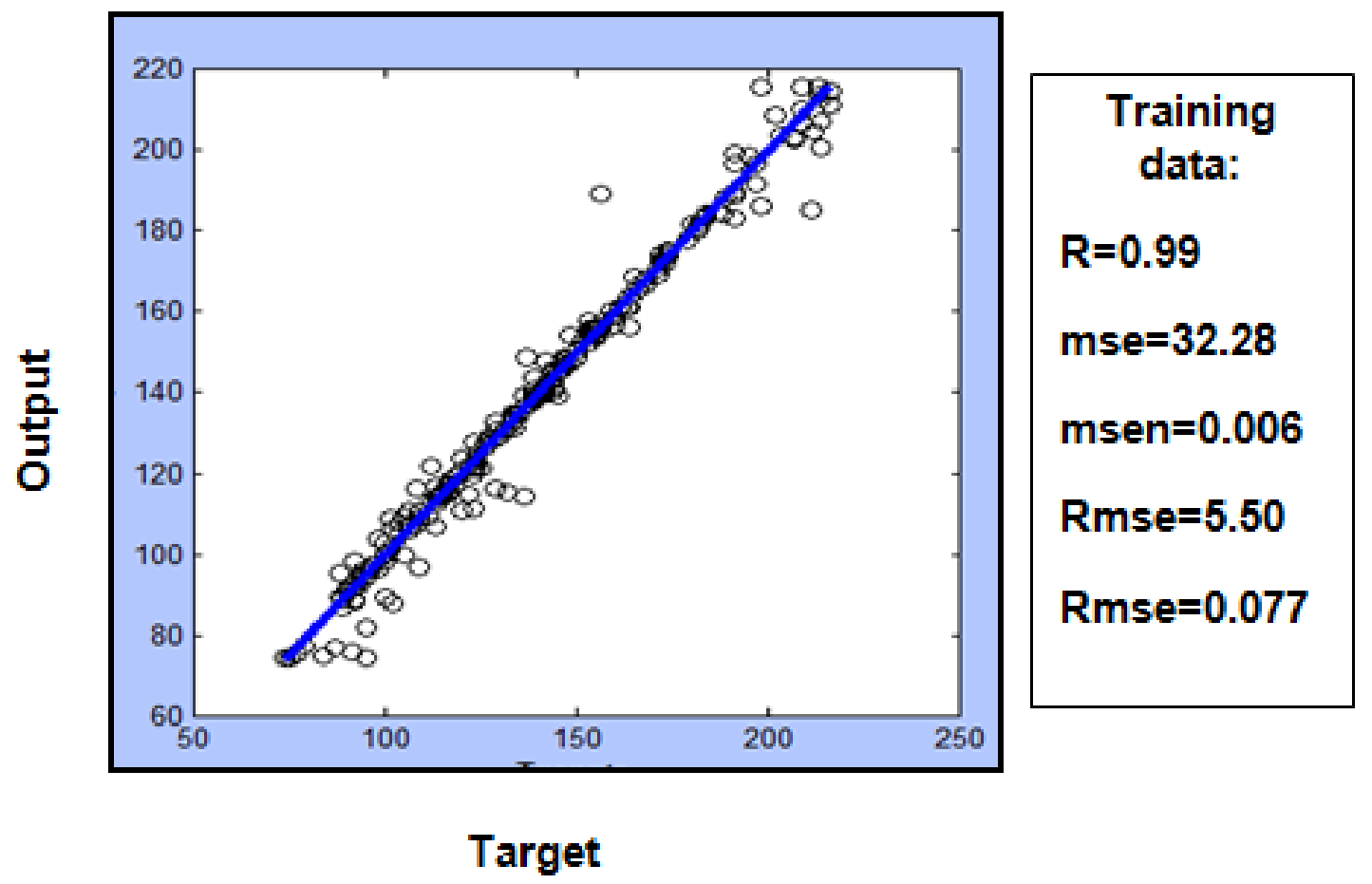

Figure 8. Values of $R-M S E-R M S E$ for training data set 


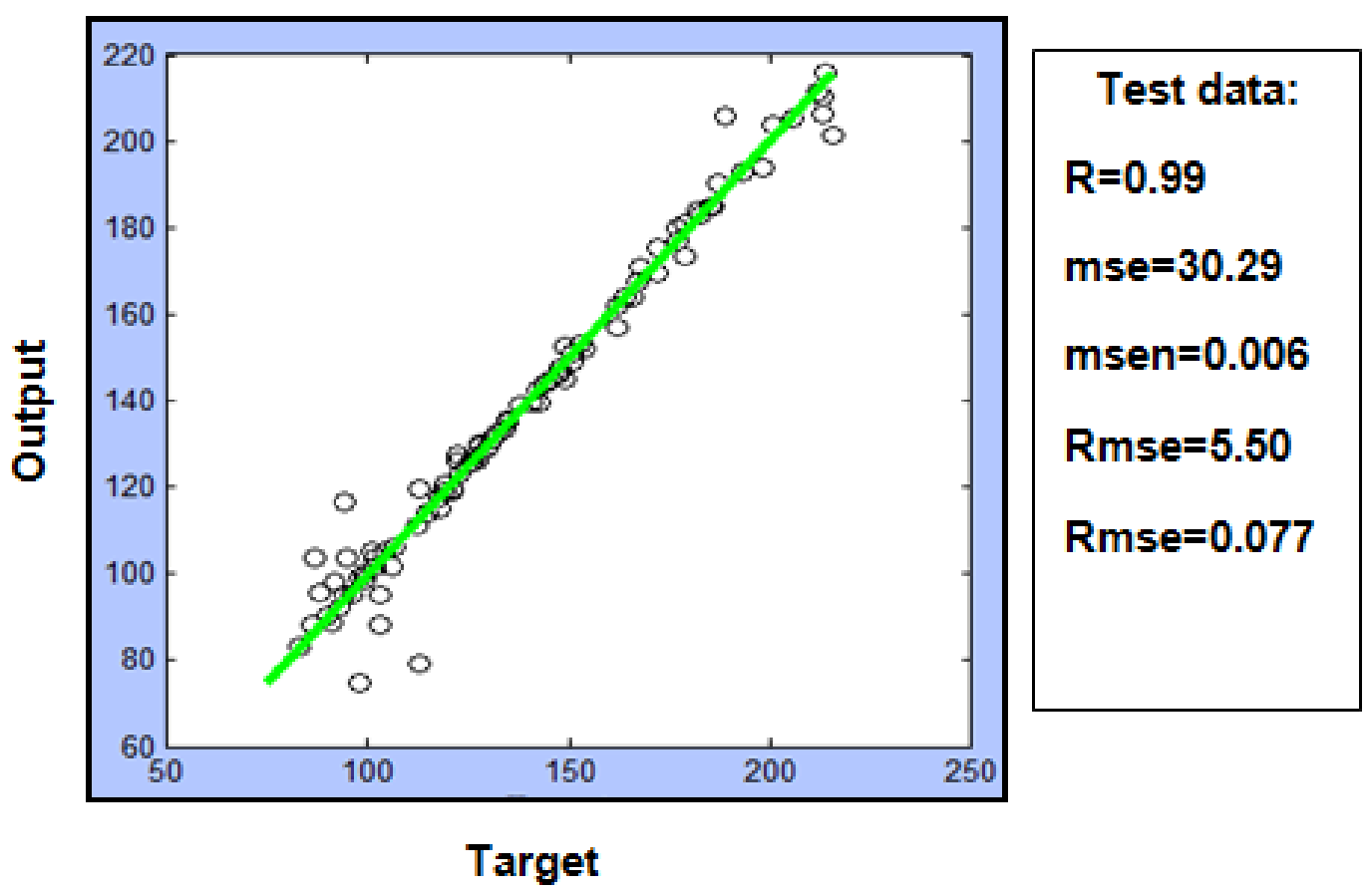

Figure 9. Values of $R$ - MSE - RMSE for test data set

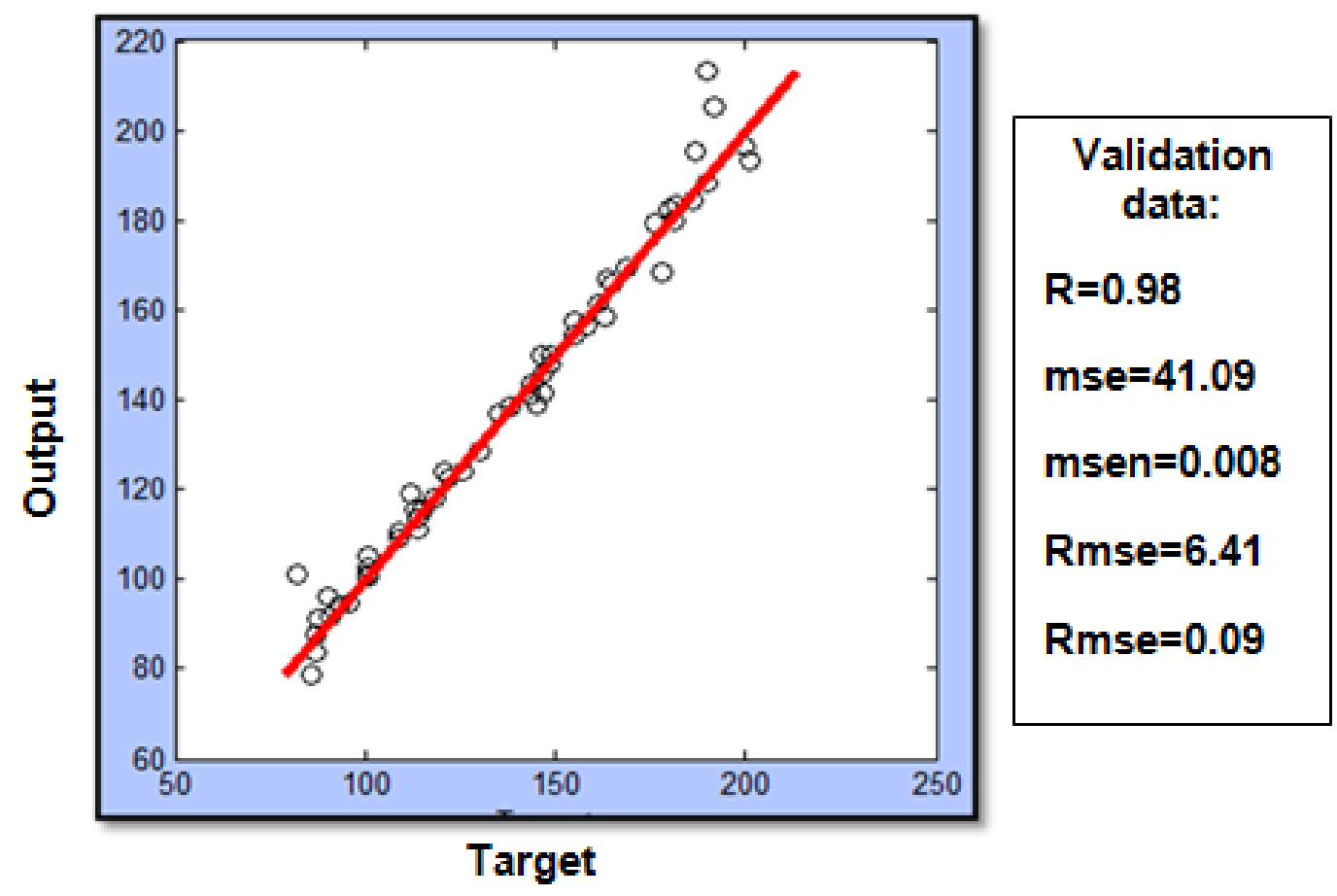

Figure 10. Values of $R$ - MSE-RMSE for validation data set 
Since the artificial neural network considers a number of data to learn the networks and some data and some data in order to avoid duplicate network training mode,that is the network validation phase, it also chooses some data in order to extend the network, which is network test data. Model prediction is shown in (Fig. 11).

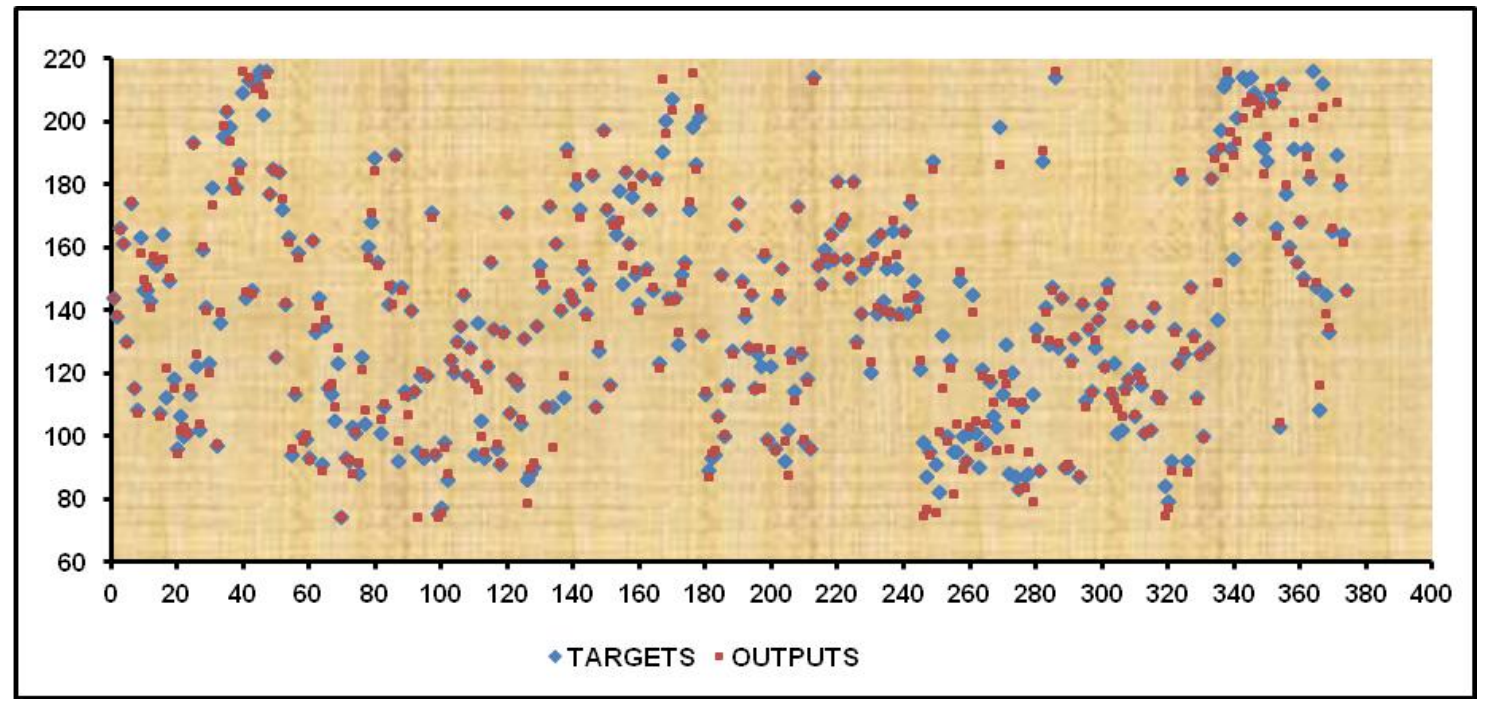

Figure 11. The results of model prediction against the actual values of the treatment plant

Sensitivity analysis allows the level of accuracy required for a parameter to be considered so that the model is valuable and useful enough. Sensitivity analysis can also be used to determine what parameter values are reasonable to be in the model (Vilimek, 2014). In this study, because of the complex environmental, physical and chemical process of factors in the treatment plants and the non-linear behavior among them, a decrease or increase in one does not necessarily lead to increases or decreases in output variable. Hence, in order to investigate the role of each of the input parameters in the estimation of the produced sludge, the impact of weight between neurons in the input intermediate and output layer was used in the calculations, according to formula (12) (Montana and Palmer, 2003):

$$
I j=\frac{\sum_{j=1}^{N h}\left[\frac{|W i j|}{\sum_{r=1}^{N i}|W r j|}|W j k|\right]}{\sum_{i=1}^{N i}\left[\sum_{j=1}^{N h}\left[\frac{|W i j|}{\sum_{r=1}^{N i}|W r j|}|W j k|\right]\right]}
$$

where, Ni is the number of neurons in the input layer,

$\mathrm{Nh}$ is the number of neurons in the middle layer,

Wij is the weight between neurons in the input layer and the middle layer (weight between input neurons $i$ and the hidden neuron $j$ ),

$\mathrm{Wjk}$ is the weight between neurons in the middle layer and output layer (weight between hidden neuron $\mathrm{j}$ and the output neuron $\mathrm{k}$ ), 
$\sum_{r=1}^{N i}|W r j|$ : The sum of all weights between the ith input neurons and jth hidden neuron.

The results are provided in (Table 3).

Table 3. Results of sensitivity analysis on the input data

\begin{tabular}{ll}
\hline Input data & $\mathbf{I}_{\mathbf{j}}$ \\
\hline Turbidity & 31.41 \\
$\mathrm{pH}$ & 30.83 \\
Temprature & 15.19 \\
\hline $\mathrm{EC}$ & 10.91 \\
$\mathrm{FeCl}_{3}$ & 4.09 \\
$\mathrm{Magnom}^{\mathrm{Flow}}$ & 2.99 \\
$\mathrm{Cl}_{2}$ & 2.32 \\
\hline
\end{tabular}

As can be seen from the table results, the most effective parameters according to the weighting coefficients between layers, in estimating the daily sludge production of water treatment plant, are, input water turbidity, $\mathrm{pH}$, temperature, electrical conductivity and the coagulant used in the process, respectively.

\section{Conclusion}

Given the diverse world-wide applications of sludge from water treatment plants in recent years, which can be used in many different industries, with the approach of clean production methods in order to develop clean systems and to create economic and social benefits for societies, including the production of light-weight bricks by combining the sludge resulting from water treatment plant and rice bran in creating green and ecofriendly future buildings, (Chianga et al., 2009), use of sludge produced by water treatment plants in the structure of clay products such as clay bricks can also be a good alternative instead of clay used in their composition (Hegazy et al., 2012). Use of the sludge from the water treatment plant as an alternative to the cement used in the manufacture of tiles and paving slabs can lead to a significant reduction in the production costs of the industry and also provides a healthy and environmentally friendly option for disposal of sludge from water treatment plants (Wolff et al., 2014). According to various studies on the use of sludge from water treatment plants, it is necessary to accurately predict the daily quantity of the sludge from a water treatment plant with the process governing it. So, it is recommended to use artificial neural network as a powerful mathematical model capable of modeling and creating nonlinear relationships between independent and dependent variables. The results (high regression and low grid error) as well as the self-evaluation and self-monitoringcapability of this software toward generalizability and to prevent its overfitting shows the high capability of artificial neural network as a powerful instrument to predict daily values of sludge produced by water treatment plant oxylator unit. This means, having high functionality and technology has a considerable speed in data analysis. Neural Network Models are 
used for prediction and classification in cases where classic statistical methods cannot be used because of their limitations. Artificial Neural Networks can be used for modeling water and sewage treatment plants process because of their high accuracy and perfect application in engineering (Neelakantan, 2001).

\section{REFERENCES}

[1] American Water Works Association. (1981): Lime Softening Sludge Treatment and Disposal. - Journal of AWWA 73: 600-608.

[2] Chiang, K. Y., Chou, P. H., Hua, C. R., Chien, K.L., Cheeseman, C. (2009): Lightweight bricks manufactured from water treatment sludge and rice husks. - Journal of Hazardous Materials 171: 76-82.

[3] Cronbach, L. J. (1951): Coefficient Alpha and the Internanal Structure of Tests. - Journal of Psychology 19: 297-234.

[4] Djeddou, M., Achour, B. (2015): The use of a neural network technique for the pridiction of sludge volume index in municipal wastewater treatment plant. - Journal of Larhyss 24:351-370.

[5] Funes, E., Allouche, Y., Beltrán, G., Jiménez, A. (2015): Artificial neural networks as tool for control food industry process. - Journal of Sensor Technology 5: 28-43.

[6] Geiser, K. (2001): Cleaner production perspectives 2: integrating CP into sustainability strategies. - Journal of Industry and Environment 24: 33-36.

[7] Ghazinoory, S., Huisingh, D. (2006): National program for cleaner production (CP) in Iran: a framework and draft. - Journal of Cleaner Production 14:194-200.

[8] Giannetti, B.F., Bonilla, S.H., Silva, I.R., Almeida, C.M.V.B. (2008): Cleaner production practices in a medium size gold-plated jewellery company in Brazil when little changes make the difference. - Journal of Cleaner Production 16: 1106-1117.

[9] Hegazy, B.E., Fouad, H.A., Hassanain, A.M. (2012): Incorporation of water sludge, silica fume, and rice husk ash in brick making. - Journal of Advances in Environmental Research 1:83-96.

[10] Huang, C., Pan, J.R., Liu, Y. (2005): Mixing water treatment residual with excavation waste soil in brick and artificial aggregate making. - Journal of Environmen Engineering 131: 272-277.

[11] Lee, D.S., Park, J.M. (1999): Neural network modeling for on-line estimation of nutrient dynamics in a sequentially-operated batch reactor.- Journal of Biotechnology 75: 229239.

[12] Montano, J. J., Palmer, A. (2003): Numeric sensitivity analysis applied to feed forward neural networks. - Journal of Neural Computing \& Applications 12:119-125.

[13] Muthupriya, P., Subramanian, K., Vishnuram, B. G. (2011): Prediction of compressive strength and durability of high performance concrete by artificial neural networks. Journal of optimization in civil engineering 1:189-209.

[14] Neelakantan, T. R., Brion, T. R., Lingireddy, S. (2001): Neural network modeling of cryptoposporidium and giardia concentrations in delware river, USA. - Journal of Water Science and Technology 43:125-132.

[15] Nourani, V., Rezapour Khanghah, T., Sayyadi, M. (2013): Application of the artificial neural network to monitor the quality of treated water. - Journal of Management \& Information Technology 1:38-45.

[16] Rak, A. (2012): Modelling of critical water quality indicators for water treatment plant. Publishing Intech. - Web: http://www.intechopen.com/books/cutting edge research in new technologies. 
[17] Satheesh Kumar, J., Poongodi, P., Balakumaran, P. (2013): Artificial intelligence based alum dosage control in water treatment plant. - Journal of Engineering and Technology 4:3344-3350.

[18] Sengul, A. B., Gormez, Z. (2013): Prediction of optimal coagulant dosage in drinking water treatment by artificial neural network. International Conference, Improving efficiency of water systems in a changing natural and financial environment. https://www.researchgate.net/publication/261477489

[19] Sun, Y., Wendi, D., Kim, D. E., Beale, M. H., Liong, S. Y. (2016): Application of artificial neural networks in groundwater table forecasting - a case study in a Singapore swamp forest. - EGU Publishing. http://www.hydrol-earth-syst-sci.net/20/1405.

[20] Vilimek, M. (2014): An artificial neural network approach and sensitivity analysis in predicting skeletal muscle forces. - Journal of Acta of Bioeng and Biomech 16:119-127.

[21] Visvanathan, C., Kumar, S. (1999): Issues for better implementation of cleaner production in Asian small and medium industries. - Journal of Cleaner Production 7:127134.

[22] Vyas, M., Modhera, B., Vyas, V. et al. (2011): Performance forecasting of common effluet treatment plant parameters by artificial neural network. - Journal of Engineering and Applied Sciences 6:38-42.

[23] Wolff, E., Schwabe, W.K., Conceiçao, S.V. (2014): Utilization of water treatment plant sludge in structural ceramics. - Journal of Cleaner Production 96: 282-298.

[24] Zarkovic, D.B., Todorovi, Z.N., Rajakovi, L.V. (2011): Simple and cost-effective measures for the improvement of paper mill effluent treatment e - a case study. - Journal of Cleaner Production 19:764-774. 